\title{
Author Correction: Genetically engineered cerebral organoids model brain tumor formation
}

Shan Bian (D), Marko Repic, Zhenming Guo (D), Anoop Kavirayani, Thomas Burkard (D), Joshua A. Bagley (D),

Christian Krauditsch (D) and Jürgen A. Knoblich (D)

Correction to: Nature Methods https://doi.org/10.1038/s41592-018-0070-7, published online 23 July 2018

In the originally published paper, the "before" image for the afatinib condition in Fig. $6 \mathrm{c}$ was incorrect. Instead of an image displaying a GBM-3 neoplastic organoid before afatinib treatment, this panel showed an image from the GBM-2 control (DMSO) group before treatment. This error has now been corrected in the HTML and PDF versions of the article; the "before, afatinib" panel in Fig. 6c now shows a representative image from the indicated experiment. The color of all error bars in Fig. 6 has also been changed to black, for consistency. All statistical analysis and all conclusions presented in the article are unaffected by this error. Nevertheless, we apologize for the mistake.

Original

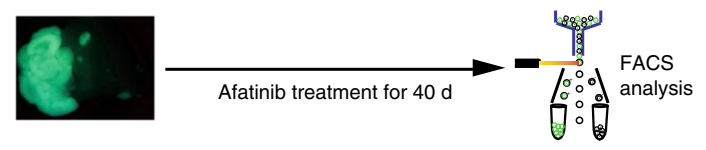

b
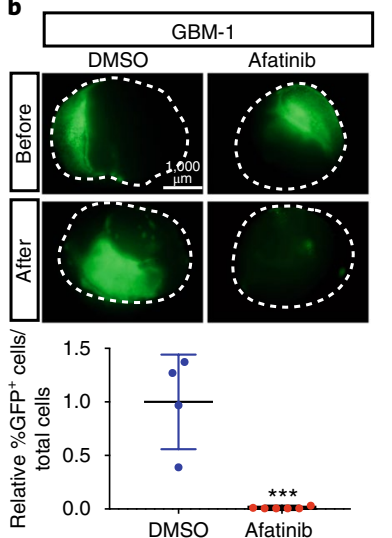

d
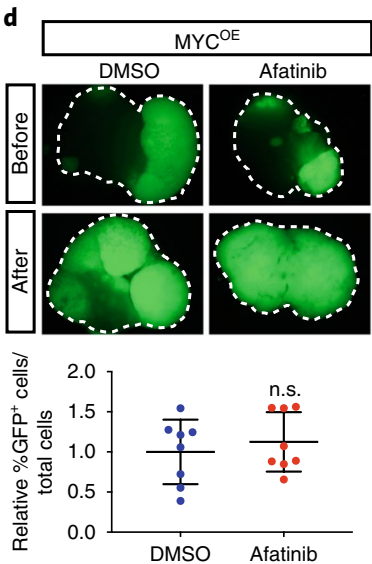

c
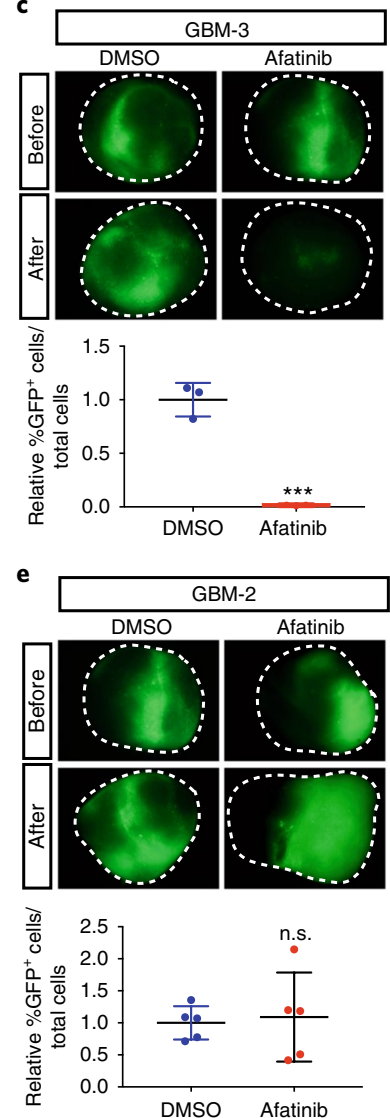

Corrected

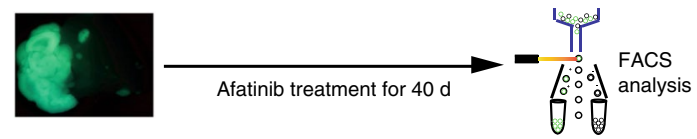

b

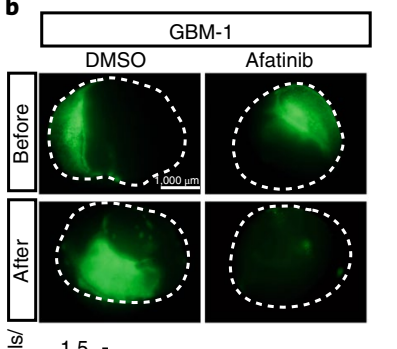

C \begin{tabular}{|c|}
\hline \multicolumn{2}{|c|}{ GBM-3 } \\
\hline DMSO
\end{tabular}
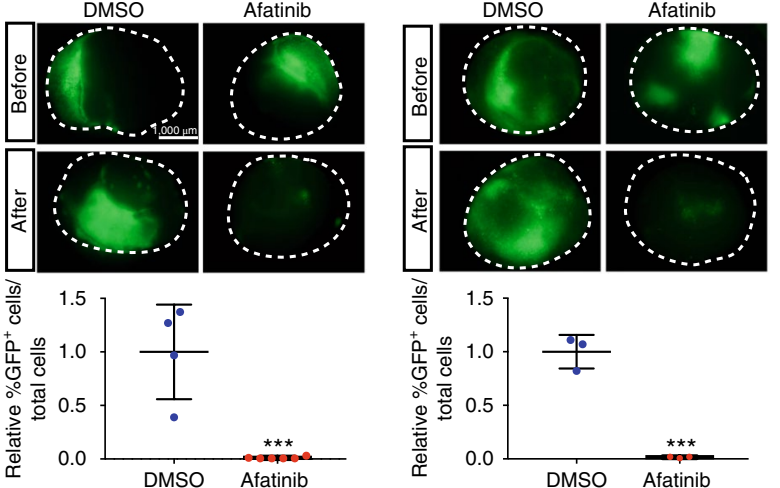

क्ञ
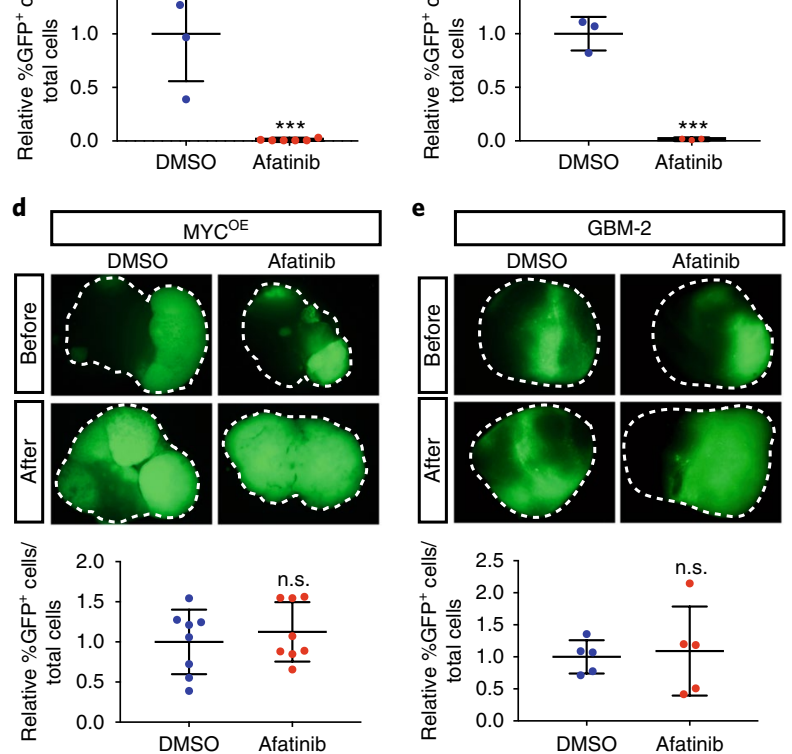

Fig. 6 | Original and corrected versions. 